\title{
Silicon nitride materials for hot working of high strength metal wires
}

\author{
R. Danzer ${ }^{1 *}$, M. Lengauer ${ }^{2}$ \\ ${ }^{1}$ Institut für Struktur- und Funktionskeramik, Montanuniversität Leoben, Peter-Tunner Strasse 5, \\ 8700 Leoben, Austria \\ ${ }^{2}$ FH JOANNEUM GmbH, Alte Poststrasse 149, 8020 Graz, Austria \\ *robert.danzer@unileoben.ac.at
}

Keywords: $\mathrm{Si}_{3} \mathrm{~N}_{4}$, Fracture, Fatigue.

\begin{abstract}
For hot rolling wires, tools are nowadays made of cemented carbides. In service, these rollers suffer from wear and thermal fatigue. Due to the properties of ceramics, their use could cause improvements in tool behaviour. In field tests - when rolling materials with high deformation resistance - cracks developed in the silicon nitride rollers, which grew for a long time period before large parts of the rollers broke apart. In more moderate rolling conditions the rollers operated safely.

A FE model is used to analyse the in-service behaviour of cracks in the silicon nitride rollers. For the observed crack path the stress intensity factor of the cracks is determined using the weight function method. It increases up to a crack depth of around $0.35 \mathrm{~mm}$ and then decreases again with increasing crack depth. This explains the observed pop-in-type growth of cracks after an overload. Depending on the rolled materials, the popped in cracks have a length of up to $1.2 \mathrm{~mm}$. The further growth of the cracks to a length of several millimetres, which is caused by a fatigue growth mechanism, needs several thousand additional revolutions.
\end{abstract}

\section{Introduction}

In the rolling mill of Boehler Edelstahl Kapfenberg in Austria metallic wires with a diameter from 5 to $13.5 \mathrm{~mm}$ are produced by hot rolling. Cemented carbides were used successfully as material for the rolling tools over decades [1]. The lifetime of cemented carbides rollers is restricted by wear, which causes a roughening as well of the tools as of the wire surfaces, which may cause a serious loss of wire quality (strength) [2]. At very high operating temperatures cemented carbides rollers suffer for thermal fatigue cracking which has similar consequences [2, 3].

In the last years the demand for high strength wires (steels and nickel-base superalloys) grew continuously. The rolling of these materials requires increasingly demanding processing conditions, which - for the processing of some types of superalloy wires - may be described by rolling temperatures up to $1100{ }^{\circ} \mathrm{C}$, where the materials still possess a flow stress of about $750 \mathrm{MPa}$ [2], which is twice as much as the strength of structural steel at room temperature. These severe loading conditions cause an increase of the problems described above and a further reduction of tool life. Therefore there is a need for alternative, better roller materials.

Due to the outstanding properties of some ceramics, improvements of tool behaviour may be expected by the use of ceramic rollers. Ceramics are very hard, have a high elastic modulus and a high strength. They are corrosion resistant, have excellent high-temperature properties and some of them have excellent thermal shock behaviour. But ceramics are also very brittle. Therefore previous work on the implementation of ceramic rollers is very limited.

Some benefits have been claimed for the production of thinner steel tapes [4], better surface quality of rolled wires and longer tool life [5,6]. Failure of rollers was reported, when materials with a very high deformation resistance were rolled [7 - 11]. However, at other positions in the 
rolling mills, were the loading is relatively moderate (e.g. for guiding rollers in the rolling mill of Boehler Edelstahl GmbH in Kapfenberg [9 - 11]), silicon nitride rollers are already routinely used. They have a more than ten times greater lifetime as the rollers used before, and yield a better surface quality of the rolled wires [2].

In a recent paper of the authors [10] the loading of silicon nitride rollers in operation was determined by a FE-analysis. When rolling superalloy wires having a temperature of around $1060{ }^{\circ} \mathrm{C}$, in each revolution the roller surface temperature fluctuates between around $200{ }^{\circ} \mathrm{C}$ and $900{ }^{\circ} \mathrm{C}$. Nevertheless, the resulting tensile components of the thermal stresses are very small (the compressive are not) and can be considered negligible. Significant for the roller reliability are contact stresses, which occur due to the pressure between the wire and the rollers, and which superpose with frictional stresses. When rolling high-strength superalloys the resulting tensile stress amplitudes can reach almost $600 \mathrm{MPa}$ (around $60 \%$ of the characteristic bending strength of the material) and are, therefore, high enough to cause serious damage. More details on temperature and stress fields in the rollers will be given in the next section.

In a consecutive paper [12] the behaviour of cracks in the roll groove of heavily loaded silicon nitride forming rollers was discussed. The analysis was based on the FE-model results described in $[10,11]$. For the path of cracks observed in the roll groove, the stress intensity factor of cracks was determined using the weight function method.

In this paper the results of [12] are analysed and the time dependent behaviour of the cracks in the roll groove is described. The most important factors for the life of the tools are discussed and the processing windows for safe operations are defined.

\section{Modelled situation and model assumptions}

If not mentioned otherwise the situation for a pair of silicon nitride rollers in the rolling mill of BÖHLER Edelstahl GmbH in Kapfenberg at the highest loaded position (roll stand DB03) of the mill for rolling the superalloy Inconel $625(\mathrm{NiCr} 21 \mathrm{Mo} 9 \mathrm{Nb})$ is modelled. This is the hardest material rolled in this mill. The roller diameter is $225 \mathrm{~mm}$, the depth of the circular groove is $2.65 \mathrm{~mm}$ and the roll gap measures $0.9 \mathrm{~mm}$. The rollers deform an almost circular wire $(\varnothing \approx 8.7 \mathrm{~mm})$ to an elliptical cross section (large diameter: $10.5 \mathrm{~mm}$, small diameter: $6.1 \mathrm{~mm}$ ), which causes an equivalent (von Mises) plastic deformation of $37 \%$. The wire speed is almost $10 \mathrm{~m} / \mathrm{s}$ and the roll frequency is about 12 revolutions per second. For rolling one tonne of wire about 3,000 revolutions of the rollers at DB03 are necessary. Fig. 1 shows a schematic sketch of the rollers in operation (a) and a silicon nitride roller (b).

The mill is designed to roll a high number of different steels like high-speed tool steels (HSS), hot and cold-work tool steels and more and more nickel-base alloys. Nowadays the rollers are made of cemented carbides [2]. After 500 tonnes of rolled wire at the latest (commonly a mix of the different qualities) they need a regrinding due to severe wear. The wear is localised in the middle of the roll groove and causes surface damage in the rolled wires [2].

Separate FE models were used to analyse the temperature- and the stress-fields in ceramic rollers made of silicon nitride. Details on the FE-models and the used material parameters can be found in [10.11]. For the temperature analysis the heat transfer between wire and rollers and between rollers and the cooling water was described with care. The heat transition coefficients between wire and rollers and between cooling water and rollers depends on the pressure between wire and rollers [13]. For the simulation the upper bound value $600 \mathrm{kWm}^{-2} \mathrm{~K}^{-1}$ was chosen, the heat transfer coefficient between cooling water and rollers was defined to be $20 \mathrm{kWm}^{-2} \mathrm{~K}^{-1}$. Thermal stresses were determined by a consecutive thermoelastic analysis.

The second FE model analyses the stresses in the rollers caused by the deformation of the wire. Here contact stresses and the frictional stresses become significant. For the contact stresses the deformation behaviour of the wire between the rollers is a very important feature, which is included 
in the FE model. The plastic deformation resistance of the wire material depends on temperature, plastic strain and deformation rate [14]. A further important aspect in the analysis is the friction between wire and rollers. In the literature [15] a friction coefficient of 0.25 has been reported for the situations found typical corresponding to those in DB03 which is also used in this analysis.

Modelled is the deformation of the wire material (Inconel 625) via silicon nitride rollers. The properties of Inconel 625 are taken at deformation temperature $\left(1060^{\circ} \mathrm{C}\right)$.

The properties of silicon nitride were determined experimentally on specimens cut out of ceramic rollers [11]. The material has the typical properties of a high quality industrial silicon nitride. Some data are given in Table 1.

Many properties of silicon nitride do only weakly depend on temperature (at least in the interesting temperature interval). Therefore room temperature properties are used in these cases. In the cases where significant temperature dependence exists (e.g. in the case of the coefficient of thermal expansion, CTE) the parameters are assumed to be temperature independent but worst case scenarios are used. For details see $[10,11]$.

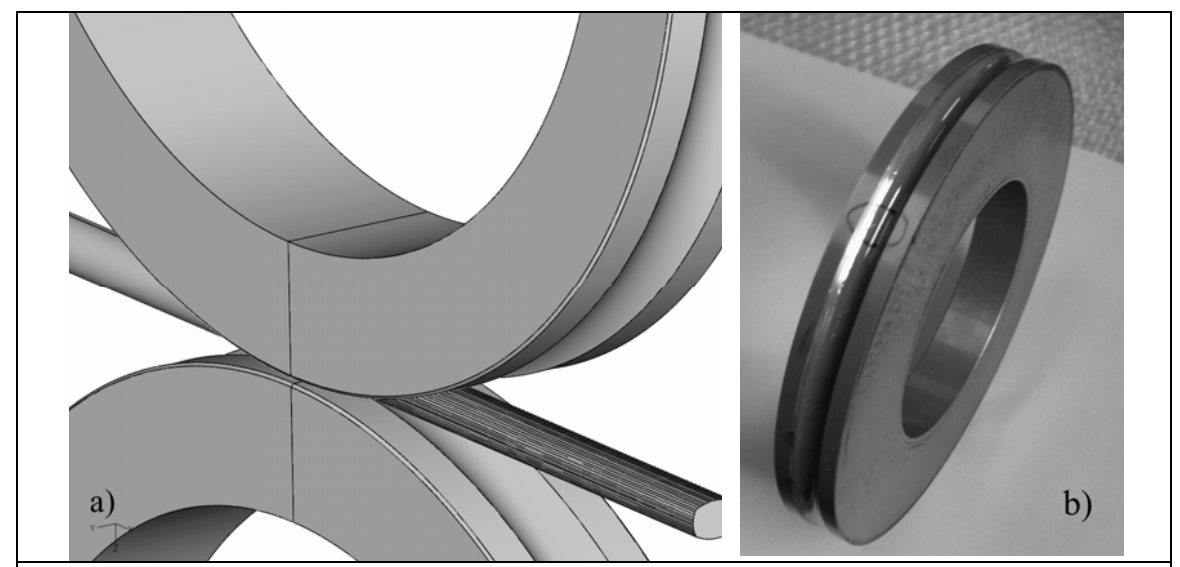

Fig. 1: Schematic sketch of a pair of rollers in operation (a) and a picture of a variant of the analysed rollers (b). The rollers (diameter $225 \mathrm{~mm}$ ) were manufactured from silicon nitride.

\begin{tabular}{|c|c|c|c|}
\hline Material properties & $\begin{array}{c}\text { HC Starck N3214 } \\
\text { measured }\end{array}$ & $\begin{array}{c}\text { FCT FSN 10 } \\
\text { measured }\end{array}$ & $\begin{array}{l}\text { Values used for } \\
\text { calculations }\end{array}$ \\
\hline Density $\rho\left[\mathrm{kg} / \mathrm{m}^{3}\right]^{+)}$ & 3224 & 3256 & 3,24 \\
\hline Hardness (Vickers, $5 \mathrm{~kg}$ ) $[\mathrm{GPa}]^{+)}$ & 15.1 & 15.1 & - \\
\hline Characteristic bending strength $\sigma_{\mathrm{b} 0}[\mathrm{MPa}]^{+)}$ & 945 & 943 & - \\
\hline $90 \%$-confidence interval of $\left.\sigma_{\mathrm{b} 0}[\mathrm{MPa}]\right]^{+)}$ & $925 \cdots 965$ & $921 \cdots 966$ & - \\
\hline Weibull modulus $m^{+)}$ & 16 & 14 & - \\
\hline $90 \%$-confidence interval for $m^{+1}$ & $12 \cdots 19$ & $11 \cdots 17$ & - \\
\hline $\begin{array}{lr}\text { Fracture toughness, } & \text { IF-method }^{+)} \\
K_{\text {Ic }}[\mathrm{MPa} \sqrt{\mathrm{m}}] & \text { SENB-S-method }^{+)}\end{array}$ & $\begin{array}{l}7.1 \\
5.4\end{array}$ & $\begin{array}{l}6.5 \\
6.4\end{array}$ & 6.4 \\
\hline 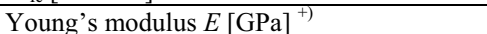 & 293 & 311 & 305 \\
\hline Poisson's ratio $\mu^{*)}$ & 0.28 & 0.28 & 0.28 \\
\hline Thermal conductivity $\lambda[\mathrm{W} / \mathrm{mK}]^{*)}$ & 25 & 30 & 25 \\
\hline Specific heat capacity $c_{\mathrm{p}}[\mathrm{J} / \mathrm{kgK}]^{*)}$ & 1100 & 1100 & 1100 \\
\hline Thermal expansion coefficient $\left.\alpha\left[\mathrm{K}^{-1}\right]^{*}\right)$ & $3.4 \cdot 10^{-6}$ & $3.2 \cdot 10^{-6}$ & $3.3 \cdot 10^{-6}$ \\
\hline
\end{tabular}

Table 1: Material properties of the Si3N4 rollers at room temperature;

+) own measurements; *) Data from producers data sheat 


\section{Temperature fields and thermal stresses}

In the rolling process a given position on the roll groove surface is in contact with the hot wire $\left(1060{ }^{\circ} \mathrm{C}\right)$ only on a short part of the circumference $[10,11]$. The contact time with the wire is about $2 \cdot 10^{-3} \mathrm{~s}$. The rest of the revolution $\left(82 \cdot 10^{-3} \mathrm{~s}\right)$ this position is cooled by water. This thermal loading causes a highly transient temperature field: In the first revolution the temperature on the roll groove surface reaches $900{ }^{\circ} \mathrm{C}$ within $2 \mathrm{~ms}$ (the "contact time"). When the contact between wire and the analysed part of the rollers ends and cooling begins, the surface temperature sharply decreases. About $10 \mathrm{~ms}$ after the beginning of the cooling, it has fallen to $200{ }^{\circ} \mathrm{C}$. At the end of the first cooling cycle the surface temperature is about $70^{\circ} \mathrm{C}$. Then the described surface element comes in contact with the hot wire again. Heating of the surface starts again and the heating procedure is repeated. In the surface region the temperature variation has almost reached a periodical steady state after the first 20 revolutions. The peak surface temperature increases to $930^{\circ} \mathrm{C}$ and the lowest surface temperature increases up to $130^{\circ} \mathrm{C}$. In the interior of the rollers the temperature also increases slightly. $1 \mathrm{~mm}$ underneath the surface the temperature variation per cycle is as small as $10{ }^{\circ} \mathrm{C}$, but the overall temperature increases up to almost $200{ }^{\circ} \mathrm{C}$ within the first 20 cycles. Deeper in the rollers the temperature, the cyclic heating and cooling can hardly be recognised but the overall temperature still (slightly) increases. For example in a depth of $6 \mathrm{~mm}$ the temperature reaches $50{ }^{\circ} \mathrm{C}$ after the first 20 revolutions. An experimental validation of these results is not easy and has not been performed, but workers report that immediately (approximately one minute) after the rolling operation is finished, the rollers are cold enough to be handled with one's bare hands. This observation fits to our calculations. More details on the calculations and results can be found in [10, 11].

The compressive strength of ceramic materials is many times higher than its tensile strength. Therefore - this is a very important difference to the behaviour of metals and cemented carbides only tensile stresses are - in general - responsible for failure. The very severe cyclic heating and cooling of the surface elements in the roll groove (between $130{ }^{\circ} \mathrm{C}$ and $930{ }^{\circ} \mathrm{C}$ ) predominantly causes large compressive stresses at the surface. Reasonable tensile stresses only occur in the interior of the rollers (more than $0.5 \mathrm{~mm}$ underneath the surface) where they reach up to $40 \mathrm{MPa}$ $[10,11]$. In comparison the (tensile) characteristic strength of the used silicon nitride ceramic is $950 \mathrm{MPa}$. In summary it can clearly be stated, that - for silicon nitride rollers - the thermomechanical stresses caused by the rolling process are completely harmless.

The same is not necessarily true if other high temperature materials are used. Thermal stresses scale with the product of Young's modulus and CTE, which is four times larger for silicon carbide than for silicon nitride. The strength of silicon carbide is about half of that of silicon nitride. For these reasons, thermal stresses in silicon carbide rollers may become problematic. In the case of cemented carbides the very large compressive stresses, which occur in the heated surface area in the roll groove, may cause thermal fatigue. In fact the occurrence of thermal fatigue cracks in the roll groove of thermally highly loaded cemented carbide rollers has been observed [2].

\section{Stresses caused by the deformation of the wire}

Due to the deformation of the wire very high contact stresses occur. More than 100 years ago Hertz has analysed the elastic contact problem of a sphere pressed onto an infinite half plane [16, 17]. Tensile stresses occur only in a very limited ring shaped region around the circular contact zone between sphere and plane. Their peak amplitude depends on the mean pressure in the contact zone and also on the elastic properties of the sphere and half plane materials. Roughly speaking the peak tensile stress in a silicon nitride half plane is about $1 / 4$ of the mean pressure. For a typical mean contact pressure of about $2000 \mathrm{MPa}$ the Hertzian tensile stresses would be around $400-500 \mathrm{MPa}$ when neglecting friction, which may become significant for silicon nitride ceramic materials. Similar or even higher stresses (due to the curvature in the roll groove and friction) can be expected 
in the ceramic roller. Therefore this situation is analysed in more detail in the FE- model mentioned above $[10,11]$.

Of course there is some relative movement between wire and roller surface, which causes some friction. If it is assumed, that the friction stresses are of the order of the contact stresses times the friction coefficient, they are also some $100 \mathrm{MPa}$. The frictional stresses are compressive as well as tensile, depending on the position in the roll groove. Therefore they are also significant for the reliability of the ceramic rollers and they also have been considered in more detail in the FEanalysis.

Results of the model calculations are shown in Fig. 2 [10, 11]. In (a) the distribution of the first principal stress over the roll groove is plotted. The zone with very high tensile stresses has a parabolic shape. It is situated a little outside the contact zone between wire and roller (which has also a parabolic shape). The maximum tensile stress is almost $600 \mathrm{MPa}$. It can be recognised, that the Hertzian analysis is a good zero order approximation of this entirely non-Hertzian contact problem.

In (b) the course of the first principal stress along the dashed line shown in (a) is plotted. The stress sharply increases up to the peak stress $(\approx 600 \mathrm{MPa}$, tension $)$ just outside the contact zone and then decreases towards the minimum $(\approx-1100 \mathrm{MPa}$, compression) just inside the contact zone. Towards the middle of the roll groove, the stress amplitude increases again. This is caused by friction. In the middle the stresses are tensile and reach about $200 \mathrm{MPa}$. It should be noted, that the direction of the first principal stress changes at different positions. At the peak load position it is almost perpendicular to the rolling direction (pure contact stresses) and in the middle of the roll groove it is parallel (caused by frictional stresses in direction of the wire movement).

In (c) the course of the first principal stress at the position of the peak load with time and in (d) perpendicular to the surface is shown. The tensile stresses increase within $2 \mathrm{~ms}$ from zero to peak load and the decrease to zero within a fraction of one ms again. Perpendicular to the surface the tensile stresses sharply decrease. Within the first $20 \mu \mathrm{m}$ they fall to about $1 / 3$ and reach zero about $2 \mathrm{~mm}$ underneath the surface.

The analysed stress field approximately scales linearly with the rolling force $[10,11]$. The peak stress is $\approx 600 \mathrm{MPa}$ when rolling Inconel $625, \approx 250 \mathrm{MPa}$ when rolling HSS S600 and $\approx 140 \mathrm{MPa}$ when rolling $\mathrm{C} 15$.

In summary significant tensile stresses occur due to contact pressure and friction, which reach about $2 / 3$ of the characteristic bending strength of the used ceramic material. Theory of brittle fracture (Weibull theory) shows that strength depends on the specimen size. Since the size of the specimens used to measure strength (bending strength, specimen size $4 \mathrm{~mm} \times 3 \mathrm{~mm} \times 40 \mathrm{~mm}$ ) is quite different from the size of the rollers, failure may become possible. But Weibull theory is only applicable if the stress amplitude along the extension of the fracture initiating crack is almost constant. Therefore behaviour of surface cracks will be studied in the next chapter.

\section{Behaviour of surface cracks in the roll groove}

In order to tackle this problem the behaviour of a circumferential surface crack at the highest loaded position in the roll groove is analysed [12]. If - for a special traction field along the crack path (reference case) the stress intensity factor is known, it can be determined for any traction field along the crack path with the weight function method $[18,19]$. The used reference case is an edge crack in an infinite half plane loaded with a homogeneous uniaxial homogeneous tensile stress state. The traction field for the crack in the roll groove is transient, since the stresses in the roll groove are transient. Therefore the tractions change from time to time. For any time the stress intensity factor can be determined. The result (the envelope over the stress intensity factors in a revolution) is shown in Fig. 3. Details of the calculation can be found in [11, 12]. 


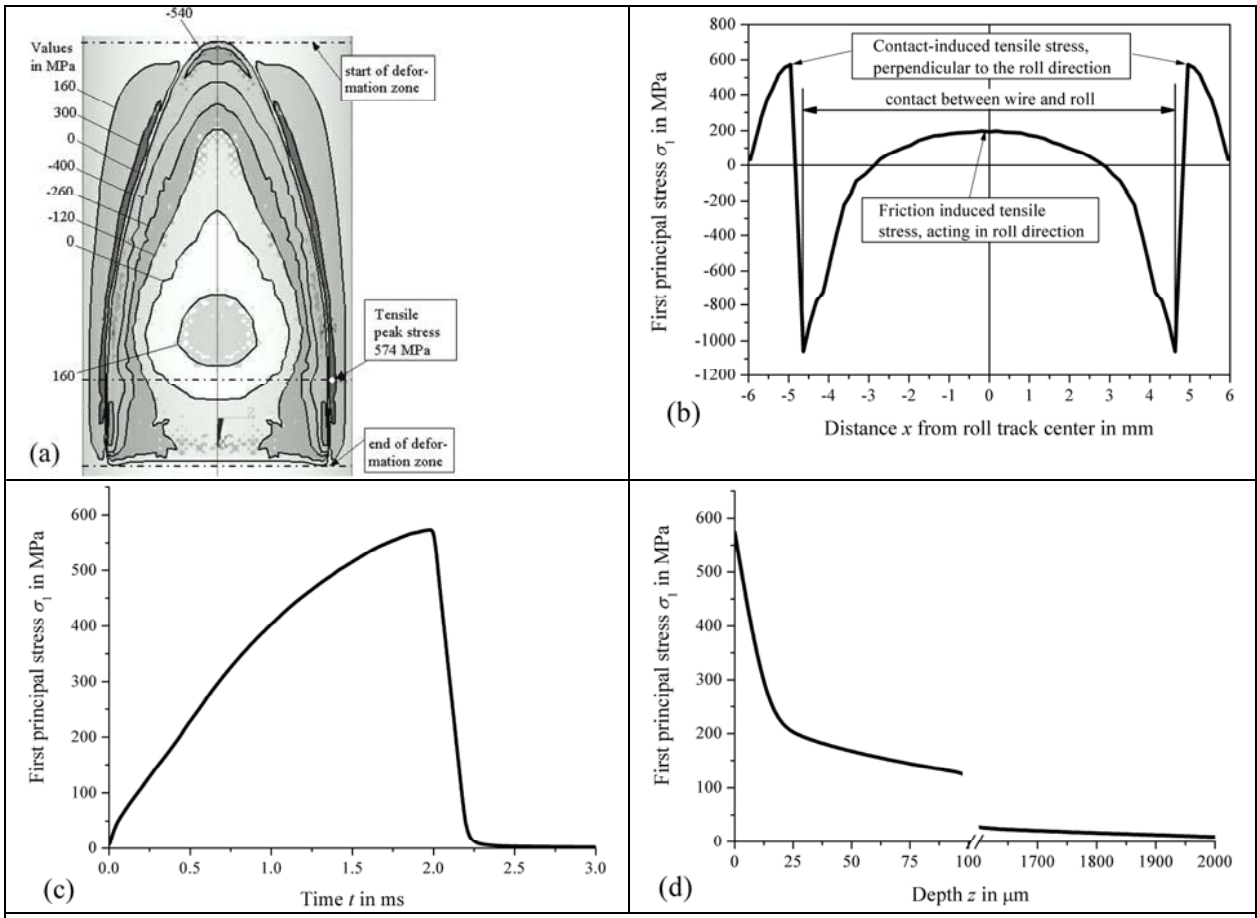

Fig. 2: First principal stresses in the rollers: a) Distribution of the stress on the surface of the roll groove on height of the tensile peak stress, b) Stresses along the dashed line shown in (a), c) Development of the first principal stress over the time at the position of the peak stress and d) Slope of the first principal stress perpendicular to the roll groove surface starting at the position of the peak stress.

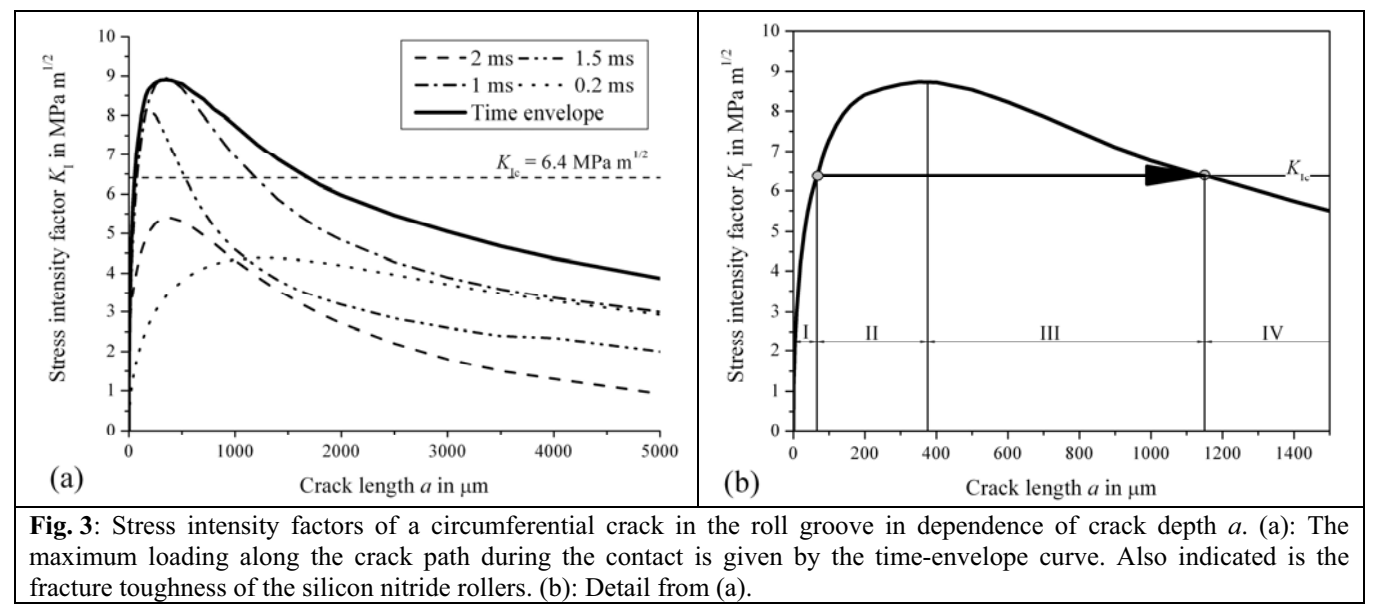

It is interesting to note that each of the temporal stress intensity factors own a maximum and that - depending on the time - these maxima of the stress intensity factors are positioned at different points along the crack path. Thus the maximum loading has to be described by the time envelope. In 
the analysed cases the maximum of the envelope is at a crack depth of about $350 \mu \mathrm{m}$. Also shown in Fig. 3 is the fracture toughness of the investigated silicon nitride ceramic.

The behaviour of the cracks depends on their length. For a crack in region I (Fig. 3.b) the stress intensity factor is smaller than the fracture toughness at any time and the crack will not grow by brittle fracture. For a crack in region II the stress intensity factor increases with time. At a determined time it exceeds the fracture toughness and the crack will spontaneously grow. But with increasing crack depth (right to the maximum) the stress intensity factor decreases again. The crack stops, if it falls below the stress intensity factor (pop in behaviour of the crack). If the stress intensity factor further increases with time, the crack stably extends up to the end of region III. Now all cracks should have the same depth (except those which was longer at the beginning, region IV), which is - in the analysed case around $1.2 \mathrm{~mm}$. Cracks in region IV do not extend by spontaneously crack growth.

In fact - in some cases - cracks of several millimetres depth were found in ceramic rollers after severe rolling operations (e.g. after a few tonnes of superalloy wire rolling), which did not cause catastrophic failure (the rollers could be further used). This is a strong experimental hint that the pop in behaviour described above really exists and that - for a high enough crack depth - the stress intensity factor decreases with increasing crack depth.

Of course the stress intensity factor depends on the rolling conditions. It increases with increasing deformation resistance. The peak stress intensity factor is $2.1 \mathrm{MPa} \sqrt{\mathrm{m}}$ when rolling $\mathrm{C} 15$, 3.6 MPa $\sqrt{\mathrm{m}}$ when rolling HSS $\mathrm{S} 600$ and $8.8 \mathrm{MPa} \sqrt{\mathrm{m}}$ for Inconel 625 . The course of the stress intensity factor of a circumferential crack (at peak stress position) is shown in Fig. 4 for rolling different wire qualities.

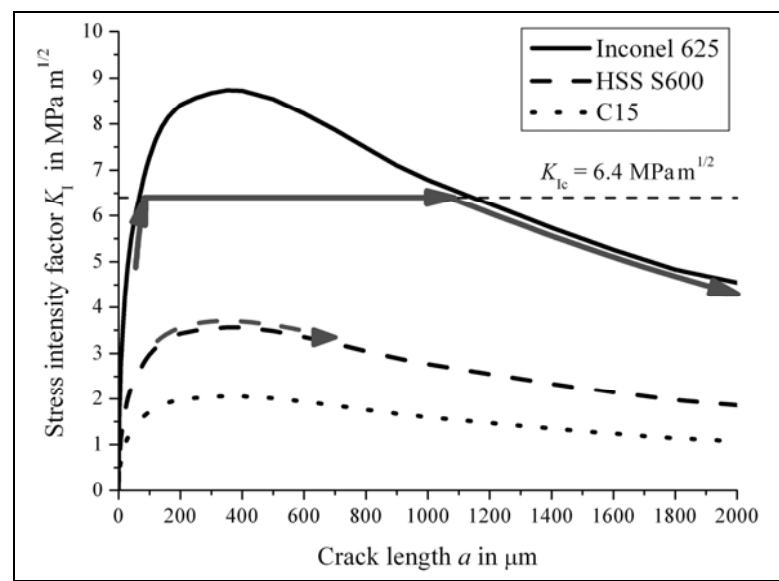

Fig. 4: Stress intensity factor ( $K$ ) versus crack depth for a circumferential crack at the peak stress position. Shown are curves for the situation when rolling C 15, HSS S600 and Inconel 625 respectively. At peak stress position the minimum stress in a revolution is zero and the stress intensity factor equals to the range of the stress intensity factor ( $K=\Delta K$ ). The crack extension by fatigue and spontaneously crack growth is indicated by arrows.

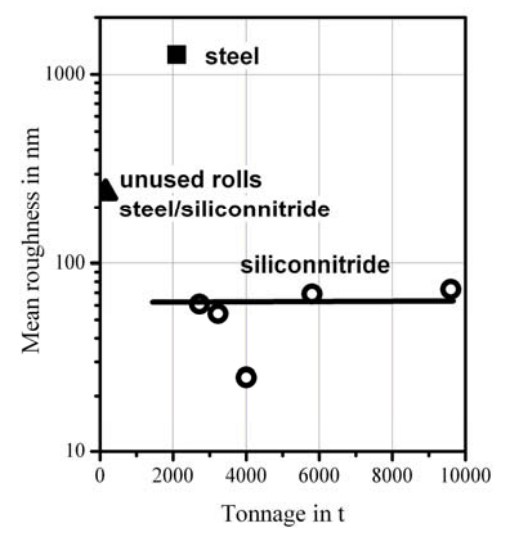

Fig. 6: Surface roughness ( $R_{a}-$ value) versus amount of rolled wire. In service the roughness of the steel rollers increases but the roughness of the silicon nitride rollers decreases.

\section{Subcritical crack growth}

In ceramic materials a crack growth mechanisms has been recognised, which also occurs at stress intensity factors smaller than the fracture toughness [20, 21] (e.g. cracks extend under a constant load). Subcritical crack growth is sometimes also called slow crack growth or static fatigue [21, 22]. 
It is thermally activated [22]. It has been recognised that the crack growth rate can be described by a Paris type law [20 - 22]:

$$
v=v_{0} \cdot\left(\frac{K}{K_{\mathrm{Ic}}}\right)^{n} \quad \text {, for } \quad K<K_{\mathrm{Ic}} .
$$

For $K \geq K_{\text {Ic }}$, brittle fracture occurs. $v_{0}$ and $n$ are material parameters. The fracture toughness $K_{\text {Ic }}$ is used as a scaling parameter. Determination of subcritical crack growth data is difficult and time consuming and only few data can be found in the literature. For a material similar to the material used for the rollers data are published in [23] yielding $n=30$ and $v_{0} \approx 10^{-6} \mathrm{~s}^{-1}$. This equation is approximately true (or a higher bond) from RT to $800{ }^{\circ} \mathrm{C}$.

An effective loading time per cycle can be defined $\left(\Delta t_{\text {eff }}\right)$, which is the time under the tensile peak load $\sigma_{\max }$ within a loading cycle $\Delta t$, which causes the same crack advance as the real loading:

$$
\Delta t_{\text {eff }} \leq \int_{0}^{\Delta t}\left(\frac{\sigma(t)}{\sigma_{\max }}\right)^{n} \mathrm{~d} t
$$

At the peak load position in the roll groove the course of the stress with time is shown in Fig. 2.c. Inserting in Eq. 2 and integrating using $n=30$ gives an effective loading time per cycle of $\Delta t_{\text {eff }} \leq 5 \cdot 10^{-6} \mathrm{~s}$. An upper limit for the subcritical crack growth rate is: $K=K_{\text {Ic }}$, where $v=v_{0}$. Therefore an upper limit for the crack growth per revolution is

$$
\Delta a_{\mathrm{r}}=v_{0} \cdot \Delta t_{\mathrm{eff}},
$$

which is in the order of about $5 \cdot 10^{-11} \mathrm{~m} /$ revolution. This upper bond for the subcritical crack growth (which is based on an extreme conservative estimation) suggests, that the deepening of the crack is much smaller than the loss of surface material by wear (evaluation of field test results indicate the existence of linear wear with a wear rate of about $2 \cdot 10^{-10} \mathrm{~m} /$ revolution, see over next chapter). Therefore - in service - pre-existing cracks should be "polished out" by wear and subcritical crack growth is not important in the analysed case.

\section{Fatigue crack growth}

Cyclic fatigue is a further crack growth mechanism known to exist in ceramic materials [20, 21, 24, 25]. A typical fatigue damage mechanism in ceramic materials is the breaking of crack bridges during the unloading part of the loading cycle. In this paper the question is addressed, if cracks, which exist around the peak load position in the roll groove, can grow by cyclic fatigue. In general the fatigue crack growth rate (i.e crack growth per load cycle $\Delta a / \Delta N$ ) can be described by the Paris law $[20,21]$

$$
\Delta a / \Delta N=(\Delta a / \Delta N)_{0} \cdot\left(\frac{\Delta K}{K_{\mathrm{Ic}}}\right)^{m},
$$

where $(\Delta a / \Delta N)_{0}$ and $m$ are material parameters and $\Delta K$ is the range of the stress intensity factor (difference of the maximum minus the minimum of the stress intensity factor in a revolution). Again the fracture toughness $K_{\mathrm{Ic}}$ is used as a scaling parameter. 
The behaviour of a circumferential crack at the position of the peak stress is analysed. The stress intensity factor scales with the first principal stress. Its temporal development during a revolution is shown in Fig. 2.c. The maximum stress in the cycle is the peak stress and the minimum stress in the cycle is equal to zero. In this case the range of the stress intensity factor is equal to the maximum: $\Delta K=K$. The course of the stress intensity factor (and of the range of the stress intensity factor) of a circumferential crack at the peak stress position with crack depth is plotted in Fig. 4.

A small crack (a crack in region I) can grow by fatigue. With increasing crack depth the stress intensity factor increases also until it reaches the fracture toughness. Then the crack will spontaneously extend to the end of region III (pop in behaviour). Further crack growth (in region IV) may again occur by fatigue. In this region the stress intensity factor decreases with increasing crack depth. This also causes a decreasing crack growth rate. This behaviour is also shown in Fig. 4.

The number of cycles to failure can be determined by solving the integral

$$
N_{\mathrm{f}}=\int_{a_{0}}^{a_{\mathrm{f}}} \frac{1}{(\Delta a / \Delta N)} \mathrm{d} a,
$$

where $a_{0}$ is the crack depth in the roll groove after grinding and $a_{\mathrm{f}}$ is the crack length which defines the failure of the rollers.

Two rolling experiments in the rolling mill of Boehler Edelstahl in Kapfenberg (see also next chapter), where severe fatigue crack growth has occurred, were used to fit the Paris parameters in Eq. 4. In the first experiment the tensile peak stress was $574 \mathrm{MPa}$ and 5 tonnes of wire (Inconel $625)$ were rolled up to the failure of the rollers $\left(a_{\mathrm{c}}=5 \mathrm{~mm}\right)$. In the second experiment the tensile peak stress was $525 \mathrm{MPa}$ and 45 tonnes of wire (also Inconel 625) were rolled up to the failure. It is assumed that surface cracks (machining cracks) with a depth of $30 \mu \mathrm{m}$ existed in the as delivered rollers in the area of peak stress (see also next chapter). These cracks can be modelled by a straight through surface crack giving a peak SIF of $K \approx 8.9 \mathrm{MPa} \sqrt{\mathrm{m}}$ in the first and of $K \approx 8.1 \mathrm{MPa} \sqrt{\mathrm{m}}$ in the latter case. It is further assumed that crack growth occurs by cyclic fatigue and that the Paris law (Eq. 4) exists. Lifetime is described by Eq. 5. Then the Paris parameters are:

$$
(\Delta a / \Delta N)_{0}=10^{-3} \mathrm{~m} / \text { revolution }
$$

and

$$
m=21
$$

The crack growth rate versus the stress intensity range is shown in Fig. 5. Also shown are some data from the literature [26-32]. The data from Eq. 6 coincide surprisingly well with the data from the literature.

\section{Experiments and discussion of results}

Silicon nitride rollers were produced by two companies: FCT [33] and HC Starck [34], Fig. 1.b. Grinding of the rollers was done by TE-KO-WE [35]. It is known that properties of ceramics may depend on details of the manufacturing process. Therefore testing specimens were not prepared separately but were cut out of rollers. A summary on material properties is given in Table $\mathbf{1}$.

\section{Wear of the rollers}


In service the surface of the rollers changed their appearance very quickly. After the production of a few tonnes of material the surface starts to glaze and looks polished. Surface roughening measurements performed on small silicon nitride guide rollers are shown in Fig. 6. Plotted is the surface roughness (the $R_{\mathrm{a}}$-value) of the rollers versus the amount of wire, which has passed the rollers in comparison to the behaviour of conventional steel rollers. After machining the $R_{\mathrm{a}}-$ value in both types of rollers is about $R_{\mathrm{a}}=250 \mathrm{~nm}$. After guiding of 2,000 tonnes of mild steel the surface roughness of conventional steel rollers increased to more than $1,000 \mathrm{~nm}$ and the rollers had to be replaced due to severe wear. In the case of silicon nitride rollers roughness decreased quickly to $R_{\mathrm{a}} \approx 70 \mathrm{~nm}$. Then it was almost constant for the rest of the rolling experiment (about 10,000 tonnes of guided wire).

This "surface polishing" was accompanied with remarkable wear. After rolling of 10,000 tonnes of wire a $0.25 \mathrm{~mm}$ thick surface layer was lost by wear. This corresponds to a linear wear rate of about $8 \cdot 10^{-12} \mathrm{~m} /$ revolution.

Similar observations were also made on the forming rollers, Fig. 1.b. A rough estimation of a linear wear rate of these heavily loaded rollers (rolling of HSS) resulted in about $2 \cdot 10^{-10} \mathrm{~m} / \mathrm{revo}-$ lution.

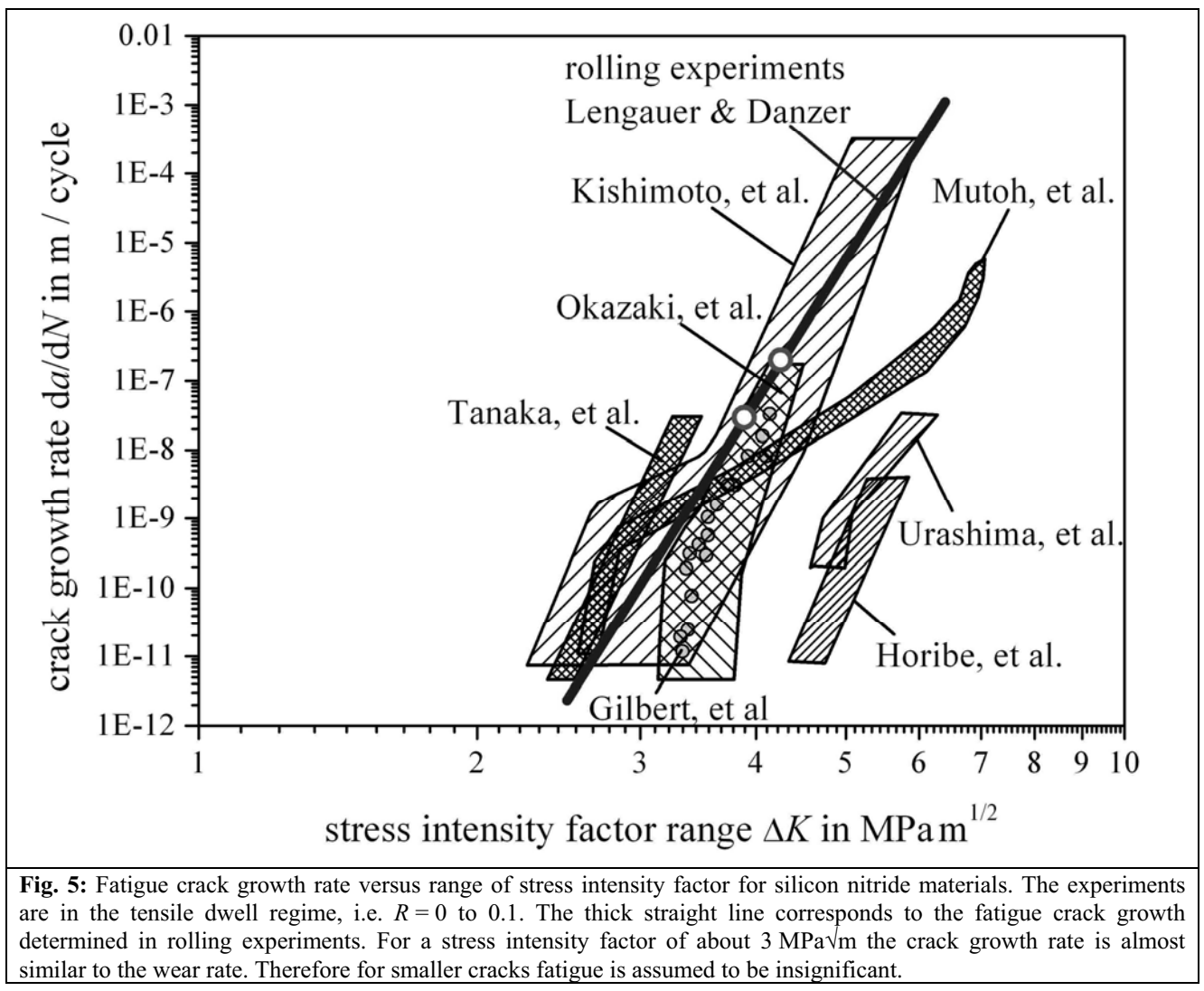




\section{Strength tests}

Standard bending specimens [26] were cut out of large forming rollers and the bending strength was determined $[26,27]$. Independent on the producer the characteristic strength of the silicon nitride roller materials was about $\sigma_{0}=950 \mathrm{MPa}$ and the Weibull modulus was about $m=15$. These are typical values for industrial produced high quality silicon nitrides.

Some small sized specimens were also machined out of finished rollers in such a way, that the ground surface of the roll groove could be used as tensile side of the bending specimens. In that way the quality of the surface in the roll groove can be assessed. This sampling was done on as delivered rollers as well as on rollers after operation. A summary of the results is shown in Table 2. For details, see also [12].

The strength of the specimens with the "as delivered" roll groove surface was much lower than that of the specimens cut out of rollers, which was used in field tests. The strength of the standard test specimens (having a surface machined under optimised conditions) was even higher. It can be assumed that strength of the small specimens is limited by surface flaws, which are caused by the machining of the roll groove.

\begin{tabular}{|l|c|c|}
\hline Tensile surface & Characteristic strength [MPa] & Weibull modulus [-] \\
\hline As defined in EN 843-1 (H.C.Starck material) & $945[925-965]$ & $16[12-19]$ \\
\hline As defined in EN 843-1 (FCT material) & $943[921-966]$ & $14[11-17]$ \\
\hline Original "as delivered" surface of roll groove & $851[709-1045]$ & $6,1[2,2-8,9]$ \\
\hline Surface of roll groove after service & $995[837-1245]$ & $7,4[2,3-9,8]$ \\
\hline \multicolumn{2}{|c|}{ Table 2: Results of bending tests on standard bending test specimens and specimens cut out of the roll groove. } \\
Numbers in brackets describe the 90\% confidence interval as defined in EN 843-5. \\
\hline
\end{tabular}

Let us analyse the depth of these machining cracks. The depth of a fracture causing crack in a strength test can be determined with the Griffith/Irwin criterion: $a_{\mathrm{c}}=(1 / \pi) \cdot\left(K_{\mathrm{Ic}} / Y \sigma_{\mathrm{f}}\right)^{2}$, where $K_{\mathrm{Ic}}=6.4 \mathrm{MPa} \sqrt{\mathrm{m}}$ is the fracture toughness, $Y=1.12$ is the geometric factor of a straight through edge crack [20] and $\sigma_{\mathrm{f}}$ is the strength of the specimen [20, 21]. For the specimens with the "as delivered" surface $\left(\sigma_{\mathrm{f}}=709-1,045 \mathrm{MPa}\right)$ the depth of the fracture initiating machining cracks ranges from 10 to $21 \mu \mathrm{m}$.

In service the relative movement between the wire and the roller surface causes some polishing of the roller surface. The strength interval of the corresponding bending test specimens ranges from 837 to $1,245 \mathrm{MPa}$. This corresponds to a depth of fracture initiating surface cracks ranging from 7 to $15 \mu \mathrm{m}$ : It is obvious, that the amount of surface damage is reduced significantly.

\section{Field tests on heavily loaded forming rollers}

Field tests on heavily loaded forming rollers ran at the rolling mill of Boehler Edelstahl in Kapfenberg, Austria. Several types of rollers were tested at several different positions (roll stands) in the wire block. Rolled were different qualities having a wide span in deformation resistance.

Rolling of mild steels, e.g. C 15: Materials having a weak or intermediate deformation resistance could successfully be rolled with silicon nitride rollers. For C 15 the stress intensity factor (SIF) of a circumferential surface crack at peak position $(2.1 \mathrm{MPa} \sqrt{\mathrm{m}})$ is smaller than $1 / 3$ of the fracture toughness $(6.4 \mathrm{MPa} \sqrt{\mathrm{m}})$ at any crack depth (Fig. 4). For machining cracks (having a depth of $30 \mu \mathrm{m}$ or less, see the above chapter) it is even as small as about $1.2 \mathrm{MPa} \sqrt{\mathrm{m}}$. Then the cracks are stable and do not grow. The fatigue growth rate is much smaller than $10^{-13} \mathrm{~m} /$ revolution for any crack length and fatigue crack growth is, therefore, not significant in any case. The most significant damage mechanism is wear.

Rolling of high speed steels, e.g. HSS S600: When rolling HSS significant wear in the roller groove was observed. The lifetime of the rollers was sensitively dependent on the quality of the 
surface. In general, when rollers were ground by TE-KO-WE [2] failing of rollers did not occur. The lifetime was similar or higher than that of conventional cemented carbide rollers. In one case a roller was reground by a not experienced machine shop (after rolling 1,000 tonnes of wire). It is assumed that severe surface damage was caused by this unprofessional machining. This pair of rollers failed after rolling further 300 tonnes of HSS wire.

When rolling HSS wires the peak SIF is a little bit more than half of the fracture toughness about $(K \approx 3.6 \mathrm{MPa} \sqrt{\mathrm{m}}$ ). For a crack depth of $a=30 \mu \mathrm{m}$ the SIF is $K \approx 2.0 \mathrm{MPa} \sqrt{\mathrm{m}}$ and the fatigue crack growth rate is smaller than $10^{-13} \mathrm{~m} /$ revolution. This is less than the wear rate and any fatigue crack growth is polished out by wear. This is in agreement with results of rolling experiments mentioned above. For $a=100 \mu \mathrm{m}$ (we assume that cracks of this depth are caused by the unprofessional maching mentioned above) the stress intensity factor is $K \approx 3 \mathrm{MPa} \sqrt{\mathrm{m}}$ and the fatigue crack growth rate is about $1.4 \cdot 10^{-10} \mathrm{~m} /$ revolution. i.e. it is comparable to the wear rate. For cracks with such depth or more fatigue crack growth becomes feasible (dashed arrow in Fig. 4). A lifetime assessment based on Eq. 5 gives a lifetime of about 315 tonnes of HSS wire rolling. This is in fair agreement with the experimental results.

Rolling of superalloys, e.g. Inconel 625: When rolling superalloys failing of the rollers (by breaking out of large pieces of the roller) occurred after rolling several tonnes to several ten tonnes of wire. It is assumed that the crack growth is caused by cyclic fatigue. This behaviour was the basic assumption for the determination of the Paris parameters (Eq. 6).

For a crack depth of $a=30 \mu \mathrm{m}$ the SIF is about $K \approx 4.9 \mathrm{MPa} \sqrt{\mathrm{m}}$. The crack growth rate at this loading is about $4 \cdot 10^{-6} \mathrm{~m} /$ revolution. Within a few revolutions the crack grows to the end of region I. Then, within the next cycle, it pops into the end of region III. Then the crack further extends in region IV by cyclic fatigue. With increasing crack length the SIF decreases and the crack growth rates slows down also. The crack needs more than $99 \%$ of the lifetime to grow to a length of several millimetres, where final failure occurs. This is a fair scenario of the observations made when rolling superalloys. This crack extension is indicated in Fig. 4 by arrows.

\section{Summary}

- When rolling superalloys the temperature in forming rollers made of silicon nitride fluctuates between RT and more than $900{ }^{\circ} \mathrm{C}$. The resulting thermal stresses are predominantly compressive and therefore harmless.

- When rolling superalloys severe tensile stresses occur in the roll groove of the rollers due to the contact pressure and by friction. These stresses are more than $60 \%$ of the bending strength of the ceramic material.

- The stress amplitude quickly decreases perpendicular to the surface of the rollers. Therefore the stress intensity factor of surface cracks has a maximum (at a crack depth of about $350 \mu \mathrm{m})$ and then decreases again. This course of the stress intensity factor explains, why small cracks pop into a depth of more than one millimetre if a high enough load is applied. In fact deep cracks were found in the roll groove of silicon nitride rollers after rolling of HSS (only in rare cases) and of superalloys (in any case).

- Three time dependent damage mechanisms seems to be possible in ceramic rollers when rolling high-strength metals and alloys: wear, subcritical crack growth and cyclic fatigue. In fact some wear were observed in rollers after rolling HSS and superalloys, which made a regrinding of the roll groove necessary. The lifetime of the ceramic rollers suffering from wear was about twice of that of cemented carbide rollers.

- Subcritical crack growth could be excluded to be serious in the analysed case.

- In the case of rolling superalloy wires the lifetime of the rollers was limited by cyclic fatigue. Improvements are possible by a roller design which reduces tensile stresses in the 
rollers [11] or by use of tougher and more fatigue resistant materials. In the case of rolling HSS significant fatigue crack growth is only possible, if deep cracks $(100 \mu \mathrm{m}$ or deeper) exist in the roll groove. This can be excluded by appropriate machining and handling.

In summary silicon nitride rollers can be used at the highest loaded positions in a wire rolling mill to process soft and hard metals and alloys (up to HSS). Application of ceramics results in extended tool life and improved surface qualities of the rolled wires. For even tougher qualities ceramic rollers can only be used at less severe loaded stands. In fact they are still used routinely at such positions (guiding rollers) in the rolling mill of Boehler Edelstahl Kapfenberg [2, 36]. 


\section{References}

[1] W. Dahl. R. Kopp and O. Pawelski: Umformtechnik, Plastomechanik und Werkstoffkunde (Verlag Stahleisen, Düsseldorf, Deutschland 1993).

[2] W. Zleppnig, private communications, (2008).

[3] W. Zleppnig, R. Danzer, F.D. Fischer and K.L. Maurer, in: Proc. ECF 6, Vol II, edited by H.C. van Elst and A. Bakker, EMAS, Warley, UK, (1986), p. 1139

[4] T. Ohkochi, K. Yasuda, M. Nakagawa: ISIJ International Vol. 32 (1992), p. 1250

[5] A. Kailer, J. Kozlowski, K. Berroth, G. Wötting, W. Zleppnig, R. Danzer and M. Lengauer: Industrie Diamanten Rundschau Vol. 37 (2003), p. 2

[6] Kailer A. and T. Hollstein (Editors.): Walzen mit Keramik (Fraunhofer IRB Verlag, Stuttgart, Deutschland 2004).

[7] Lengauer M., R. Danzer and W. Harrer in: Walzen mit Keramik edited by A. Kailer and T. Hollstein Fraunhofer IRB Verlag, Stuttgart, Deutschland, p. 95

[8] W. Zleppnig in: Walzen mit Keramik edited by A. Kailer and T. Hollstein Fraunhofer IRB Verlag, Stuttgart, Deutschland, (2004), p. 85

[9] M. Lengauer, R. Danzer, D. Rubeša, W. Harrer and W. Zleppnig: Key Eng. Mat. Vol. 290 (2004), p. 94

[10] R. Danzer, M. Lengauer, W. Zleppnig and W. Harrer: IJMR Vol. 98 (2007), p. 1104

[11] M. Lengauer: Thesis, Montanuniversität Leoben, Leoben, Austria (2007)

[12] M. Lengauer and R. Danzer: J. European Ceramic Society 28 (2008), p. 2289

[13] M. Raudensky, J. Horsky and M. Pohanka: Journal of Materials Processing Technology Vol. 125-126 (2002), p. 700

[14] D. Zhao, P. K. Chaudhury, R.B. Frank and L.A. Jackman, in: Superalloys 718, 625, 706 and Various Derivatives edited by E. A. Loria, The Minerals, Metals \& Materials Society, Warrendale, Pennsylvania, USA (1994), p. 315

[15] Z. Wusatowski: Grundlagen des Walzens (VEB Deutscher Verlag für Grundstoffindustrie, Leipzig, Deutschland 1963).

[16] H. Hertz: J. reine Angewandte Mathematik Vol. 92 (1882), p. 165

[17] B.R. Lawn: J. American Ceramic Society Vol. 81 (1998), p. 1977

[18] H.J. Petroski and J.D. Achenbach: Engineering Fracture Mechanics Vol. 10 (1978), p. 257

[19] D. Gross: Bruchmechanik (Springer Verlag Berlin, Heidelberg, Deutschland 1996).

[20] D. Munz and T. Fett: Ceramics: Mechanical Properties, Failure Behaviour, Materials Selection (Springer Verlag, Berlin, Heidelberg, Deutschland 1999).

[21] R. Danzer, T. Lube, P. Supancic and R. Damani: ADVENGMAT Vol. 10 (2008), p.275

[22] R. Danzer in: Encyclopaedia of Advanced Materials, Volume 4 edited by R.W. Cahn and R.J. Brook Pergamon Press, Oxford, UK, (1994), p. 2693

[23] T. Lube, R. Danzer, J. Kübler, J. Dusza, J.-P. Erauw, H. Klemm and V.M. Sglavo in: Fracture Beyond 2000 - Proc. of ECF 14, Vol. 2, Cracow, Poland (2002), p. 409

[24] T. Kawakubo, K. Komeya: J. American Ceramic Society Vol. 70 (1987), p. 400 
[25] C.J. Gilbert, R.H. Dauskardt and R.O. Ritchie: J. American Ceramic Society Vol. 78 (1995), p. 348

[26] H. Kishimoto, A. Ueno, H. Kawamoto and Y. Fujii: J. Soc. Mater. Sci. Jpn. 38 (1989), p. 1212

[27] Y. Mutho, M. Takahashi and A. Kanagawa in: Cyclic Deformation, Fracture, and Nondestructive Evaluation of Advanced Materials. Second Volume, ASTM STP 1184, edited by M.R. Mitchell and Otto Buck, American Society for Testing and Materials, Philadelphia (1994), p. 19

[28] M. Okazaki, A.J. McEvily and T. Tanaka: Metall. Trans. 22 (1991), p. 1425

[29] T. Tanaka, N. Okabe and Y. Ishimaru: Transactions of JSMS, Vol. 38, No. 425 (1987), p. 137

[30] C.J. Gilbert, R.H. Dauskardt and R.O. Ritchie: Cer. Int. 23 (1997), p. 413

[31] K. Urashima in: Cyclic Fatigue in Ceramics (Current Japanese Materials Research Vol.14), edited by H. Kishimoto, T. Hoshide and N. Okabe, Elsevier Science BV and The Society of Material Science, Japan (1995), p. 167

[32] S. Horibe and R. Hirahara: Acta metal. mater. 39 (1991), p. 1309

[33] K. Berroth in: Walzen mit Keramik edited by A. Kailer and T. Hollstein Fraunhofer IRB Verlag, Stuttgart, Deutschland (2004), p. 37

[34] G. Wötting in: Walzen mit Keramik edited by A. Kailer and T. Hollstein Fraunhofer IRB Verlag, Stuttgart, Deutschland, (2004), p. 23

[35] J. Kozlowski, TE-KO-WE GmbH, Beim weissen Stein 3, 56579 Bonefeld, Germany. private communications, (2007).

[36] W. Zleppnig in: Walzen mit Keramik edited by A. Kailer and T. Hollstein Fraunhofer IRB Verlag, Stuttgart, Deutschland, (2004), p. 85

[37] EN 843-1: Advanced Technical Ceramics, Monolithic Ceramics, Mechanical Properties at Room temperature, Part 1: Determination of Flexural Strength, (1995).

[38] EN 843-5: Advanced Technical Ceramics - Monolithic Ceramics - Mechanical Properties at Room Temperature: Part 5- Statistical Evaluation, (1997) 